\title{
Effect of Platelet Rich Plasma (PRP) on Proliferation of Endothelial Progenitor Cell (EPC) of Stable Coronary Artery Disease Patient
}

\author{
Ronald R Hehanusa, Andrianto, Budi S Pikir
}

\begin{abstract}
Background: Endothelial Progenitor Cell (EPC) is the progenitor of endothelial cell which has important role in regulation of vascular wall integrity and homeostasis, to protect vessels from inflamation and thrombosis, that leads into pathogenesis of coronary artery disease. Growth factors proven has important role to stimulate transduction signal in the process of proliferation of EPC. Platelet Rich Plasma (PRP) contains variety of growth factors, wellknown role in homeostasis and wound healing process. Therefore, this study was conducted to analyze the effect of PRP on proliferation of EPC of Stable Coronary Artery Disease (SCAD) patient. To analyze the effect of Platelet Rich Plasma (PRP) on the proliferation of Endothelial Progenitor Cell (EPC) from peripheral blood of patient with SCAD

Methods: This is an in vitro, true experimental, post-test only control group design. The mononuclear cells were isolated from peripheral blood of SCAD patient and cultured in M-199 medium. EPC divided into 3 groups, which received Platelet Rich Plasma (PRP), Platelet Poor Plasma (PPP), and control. After I 4 days of incubation, immunocytochemical examination was performed, EPC which marked with CD34, FITC labeled, was counted using immunofluoroscence microscope. Data analysis using ANOVA test.

Results: Cell counting showed significant increase of EPC proliferation in PRP group compared to PPP group (I.052 \pm 0.16 vs $0.762 \pm 0.19, p=0.003)$, and control group as well ( $1.052 \pm 0.16$ vs $0.068 \pm 0.05, p=<0.00 \mathrm{I})$. EPC proliferation in PPP group also increase significantly compared to control group $(0.762 \pm 0.19$ vs $0.068 \pm 0.05, p=<0.00 \mathrm{I})$.

Conclusion : Platelet Rich Plasma (PRP) increase EPC proliferation significantly from peripheral blood of SCAD patient.
\end{abstract}

(Indonesian J Cardiol. 20I9;40:258-26I)

Keywords : EPC proliferation, PRP, SCAD

Departemen Kardiologi dan Kedokteran Vaskular Fakultas Kedokteran Universitas Airlangga, RSUD Dr. Soetomo Surabaya, Indonesia.

\section{Correspondence:}

dr. Ronald Rendy Hehanusa

Departemen Kardiologi dan Kedokteran Vaskular Fakultas Kedokteran Universitas Airlangga, RSUD Dr. Soetomo Surabaya, Indonesia.

E-mail: ronaldhehanusa0I05@gmail.com

\section{Introduction}

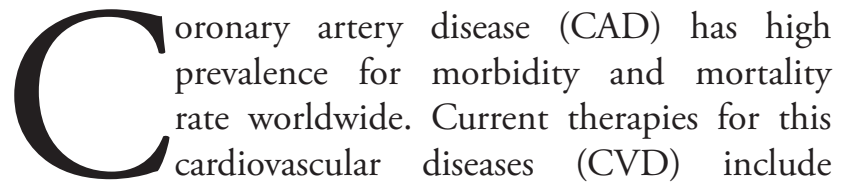
lifestyle management, pharmacological control for risk factors and revascularization, have improved the survival but not completely control the disease, 
therefore new approaches like cell-based therapy are needed ${ }^{1}$. Endothelial cell dysfunction is condition that lead to pathologic atherosclerotic in CAD patients. An increasing evidence suggest that cardiovascular risk factors affect the number and properties of EPC, the inverse correlation is found between both ${ }^{2}$. In 1997 , Asahara and his colleagues first isolated mononuclear cell (MNC) that express CD34 and VEFG-2 from human peripheral blood, named Endothelial Progenitor Cell $(\mathrm{EPC})^{3}$. This cells play an important role in the recovery and repair of injured endothelium by counteracting the detrimental CVD risks factor induced damages. Growth factors has proven role in stimulating transduction signal for proliferation of EPC and promote neovascularization ${ }^{4}$. Platelet Rich Plasma (PRP) which has minimum 5 times higher of platelets compared to baseline values for whole blood, has been used clinically in humans since 1970s for its healing properties attributed of autologous growth factors (GF) that may enhance the healing process on a cellular level ${ }^{5}$. Platelet also contains the angiogenic GF that believed promote the neovascularization process. So in this research, we woud like to know the effect of PRP on proliferation of EPC in peripheral blood of stable coronary artery disease (SCAD).

\section{Methods}

Blood samples were taken from patients with SCAD which are man, had narrowing of $\geq 50 \%$ in the left main coronary artery and $\geq 70 \%$ in one or several of the major coronary arteries from angiography. Patients with history of acute myocardial infarction, acute limb ischemia, or after revascularization therapy include stent placement or coronary artery bypass grafting (CABG) were excluded.

Written informed consent was obtained from patients before peripheral blood drawing. The protocol was approved by local ethics committee $(0421 / \mathrm{KEPK} /$ VII/2018).

\section{Preparation of PRP and Platelet Poor Plasma (PPP)}

Peripheral blood $(20 \mathrm{~mL})$ was collected from SCAD patient using anticoagulant, citrate-phosphatedextrose solution. Collected blood was centrifuged at $2400 \mathrm{rpm}$ for 10 minutes at $200 \mathrm{C}$ and the supernatant (plasma) including the buffy coat and $0.5 \mathrm{~mL}$ below buffy coat was decanted to the other tube and red blood cells (RBCs) and white blood cells (WBCs) were discarded. Secondary centrifugation was performed at $3600 \mathrm{rpm}$ for 10 minutes at $20^{\circ} \mathrm{C}$. The clear supernatant (plasma) was decanted off until $0.5 \mathrm{~mL}$ was left and the middle portion of supernatant (plasma) was taken as PPP. Finally, remaining supernatant including buffy coat and $0.5 \mathrm{~mL}$ below buffy coat was taken as PRP ${ }^{6}$.

\section{Isolation and culture of EPCs}

Peripheral blood from SCAD patient $(40 \mathrm{ml})$ was diluted with phosphate buffered saline (PBS) containing $2 \%$ of fetal bovine serum (FBS). It was then centrifuged on Ficoll-Histopaque density gradients and interface mononuclear cells (MNCs) were collected. After two washes in PBS containing $2 \%$ of FBS, pellet were taken and cells counted using hemocytometry. Each $5 \times 106 \mathrm{cell} s / \mathrm{ml}$ mononuclear diluted with M-199 stemcell expansion medium were plated on 24-fibronectin coated well plates cells, divided in to 3 groups with different treat (PRP 20\%, PPP 20\% ,and Control). Every group also given antibiotics (Penicillin and Streptomycin). Cells then incubated for 14 days at $37^{\circ} \mathrm{C}$ and $5 \%$ of $\mathrm{CO} 2$.

\section{Immunofluorescence assay}

Adherent cells were taken and washed with PBS and fixed with $3 \%$ formaldehyde for 15 minutes. Cells were stained with a FITC anti-CD34 antibody. Expression of the cells was documented with fluorescence microscope.

\section{Statistical analysis}

Data in normal distribution were reported as mean \pm SD. To analyse differences for normally distributed data, one-way ANOVA was used. Differences were considered significant if $\mathrm{p}$-values were $<0.05$. All statistical analyses were performed with SPSS for Windows (IBM Corp., Armonk, NY). 


\section{Results}

\section{PRP increase the proliferation of EPC}

In this study, Endothelial Progenitor Cells (EPC) which positive stained by CD34+ and checked by immunofluoroscence microscope (Figure 1), compared among goups treated with PRP, PPP, and control. The result showed significant increase in group treated with PRP compared to PPP in $(1.052 \pm 0.16$ vs $0.762 \pm$ $0.19, \mathrm{p}=0.003)$ and significant increase compared to control group as well $(1.052 \pm 0.16$ vs $0.068 \pm 0.05$, $\mathrm{p}=<0.001)$. EPC proliferation in PPP group also significantly increase compared to control group $(0.762$ \pm 0.19 vs $0.068 \pm 0.05, \mathrm{p}=<0.001)$.

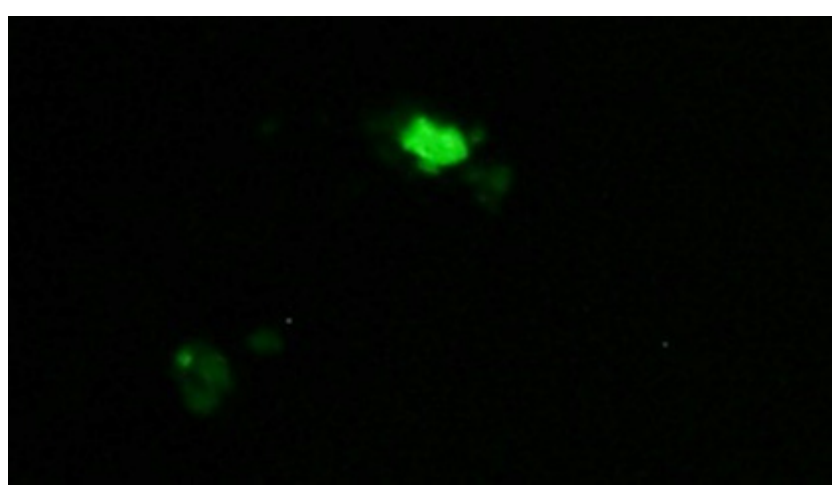

Figure 1. Immunofluorescence expression of CD34

\section{Discussion}

The result of the study showed that PRP increase the proliferation of EPC significantly compared to PPP and control group. It has been recognized that plateletes in PRP secreted various growth factors during the degranulation. Different growth factors in PRP, including vascular endothelial growth factors (VEGF), platelet-derived growth factors (PDGF), epitelial growth factors( EGF), and transforming growth factor beta 1 (TGF- $\beta 1$ ), have different role in angiogenesis and restoration of blood flow following ischemia. VEGF is the principal stimulatory factor of angiogenesis after ischemia ${ }^{7}$. VEGF causes endothelial cell proliferation and migration, which result in capillary sprouting or angiogenesis. The stimulation of PRP on angiogenesis is regulated by activation of PI 3 kinase and extracellular signal-regulated kinase $(\mathrm{ERK})^{8}$. However, neovascularization is a complex event, and interplay between cells and angiogenic factors, not VEGF only, needed to form a stable capillary vessel ${ }^{9}$. The late issue is how to optimize the potency of growth factors contained in PRP. Bir et al, shown the efficacy of sustained release of PRP in therapeutic neovascularization and this potentiation is triggered by stimulation of angiogenesis, arteriogenesis, and vasculogenesis in mouse hind limb ischemia ${ }^{10}$. We will need more studies to improve the potency of PRP in proliferation and differentiation.

\section{Conclusion}

The results of this study define that PRP increases EPC proliferation from peripheral blood of SCAD patient compared to PPP and control group.

\section{Ethical Clearance}

This study was approved by the ethic committee of Airlangga University.

\section{Conflict Of Interest}

None

\section{Publication Agreement}

The authors of this article give permission to Indonesian Journal of Cardiology to publish this article if this article is accepted

\section{Ethical Clearance}

0421/KEPK/VII/2018 from Research Ethics Committee, Dr. Soetomo Hospital, Surabaya.

\section{Publication Agreement}

The authors of this article give permission to Jurnal Kardiologi Indonesia (JKI) to publish this article in its journal if this article is accepted.

\section{Funding}

Self Funded 


\section{Acknowledgments}

Clinical Research Unit of Dr. Soetomo General Hospital, Surabaya.

Stem Cell Research and Development Center, Airlangga

University, Surabaya

\section{Conflict of Interest}

The authors declare no conflicts of interest.

\section{Funding}

There is no out source of funding.

\section{List of Abbreviations}

CABG : Coronary artery bypass graft

CAD : Coronary artery disease

CD: Cluster of differentiation

CVD : Cardiovascular disease

EGF : Epitelial growth factors

EPC : Endothelial progenitor cell

ERK : extracellular signal-regulated kinase

FBS : Fetal bovine serum

GF : Growt factor

MNC : Mononuclear cell

PBS : Phosphate buffer saline

PDGF : Platelet derived growth factor

PI3K : Phosphatidylinositol-3 Kinase

PPP : Platelet poor plasma

PRP : Platelet rich plasma

$\mathrm{RBC}:$ Red blood cell

SCAD : Stable coronary artery disease

TGF $\beta-1$ : Transforming growth factor beta 1

WBC : White blood cell

VEGF : Vascular endothelial growth factor

\section{References}

1. Sen S, McDonald SP, Coates PT, Bonder CS. Endothelial progenitor cells: novel biomarker and promising cell therapy for cardiovascular disease. Clin Sci (Lond). 2011; 120:263-283

2. Vasa M, Fichtlscherer S, Aicher A, et al. Number and migratory activity of circulating endothelial progenitor cells inversely correlate with risk factors for coronary artery disease. Circ Res 2001;89:E1-7

3. Asahara T, Murohara T, Sullivan A, Silver M, van der Zee R, Li T, Witzenbichler B, Schatteman G, Isner JM. Isolation of putative progenitor endothelial cells for angiogenesis. Science. 1997;275:964-967.

4. Yancopoulos G, Davis S, Gale N, Rudge J, Wiegand S, Holash J. Vascular spesific growth factors and blood vessel formation. Nature.2000;407:242-8

5. Mei-Dan O, Laver, Nyska M, Mann G. Platelet rich plasma-a new biotechnology for treatment of sports injuries. Harefuah. 2011; 150, no. 5, pp. 453-457.

6. Bir S, Esaki J, Marui A, Yaahara K, Tsubota H, Ikeda T, Sakata R. Angiogenic properties of sustained release platelet-rich plasma : Characterization invitro and in the ischemic hind limb of the mouse. Vasc Surgery. 2009; 50:870-8

7. Ferrara N. Role of vascular endothelial growth factor in regulation of physiological angiogenesis. Am J Physiol Cell Physiol 2001; 280:C1358-C1366

8. Brill A, Dashevsky O, Rivo J, Gozal Y, Varon D. Platelet-derived microparticles induce angiogenesis and stimulate post-ischemic revascularization. Cardiovasc Res .2005;67:30-8.

9. Carmeliet P. Mechanisms of angiogenesis and arteriogenesis. Nat Med .2000;6:389-95.

10. Bir S, Esaki J, Marui A, Yaahara K, Tsubota H, Ikeda T, Sakata R. Angiogenic properties of sustained release platelet-rich plasma : Characterization invitro and in the ischemic hind limb of the mouse. Vasc Surgery. 2009; 50:870-8 